Bornträger: Ueber eine einfache Aufarbeitung der Molybdänrückstände etc. 341

Ueber eine einfache Aufarbeitung der Molybdänrückstände, sowie über einige Erfahrungen bei der Phosphorsänrebestimmung mittelst der Molybdänmethode.

Von

\title{
H. Bornträger.
}

Bekanntlich ist es für den analytischen Chemiker eine unangenehme Arbeit, die werthvollen Molybdänrückstände von der Phosphorsäurebestimmung aufzuarbeiten. Ich habe daher nach einer einfachen Methode gesucht und theile dieselbe im Folgenden mit.

Diese Methode basirt auf der Thatsache, dass die Molybdänsäure in Ammoniak, alkalischen Laugen und starker Salpetersäure leicht löslich, hingegen in Wasser, respective schwacher Salpetersäure - selbstredend auch in anderen Säuren - fast unlöslich ist.

Ich verfahre daher folgendermaassen:

Ich gebe in eine grosse, weithalsige Glasflasche zunächst $1 / 4$ Liter Salmiakgeist, da in den Filtraten mehr Säure als Basis vorhanden ist, und giesse dann sowohl die sauren als die ammoniakalischen Filtrate direct in die Flasche. Es entsteht entweder sofort oder nach kurzer Zeit - am Besten sofort - eine krystallinische Ausscheidung der Molybdänsäure in feinen Nadeln. Dieselbe ist absolut rein. Ist die Flasche fast voll, mache ich fast neutral, lasse absitzen, filtrire durch einen Beutel oder durch ein Filter, wasche einmal ans (nicht öfter, denn sonst geht die Molybdänsäure wieder in Lösung) und presse den Niederschlag etwas ab. Alsdann löse ich denselben in möglichst wenig Salmiakgeist, wobei er sich stark erwärmt, filtrire rasch von den Verunreinigungen (Kieselsäure und Magnesia) ab and bringe das Filtrat mit Wasser auf ein specifisches Gewicht von $1,11=14^{\circ} \mathrm{Bé}$. bei $17^{\circ} \mathrm{C}$. Eine solche Lösung enthält im Liter genau $150 \mathrm{~g}$ molybdänsaures Ammon. Dieselbe giesse ich in $1 l$ Salpetersäure von 1,2 specifischem Gewicht (dargestellt aus $400 \mathrm{co}$ Salpetersäure von 1,4 specifischem Gewicht und $600 \mathrm{cc}$ Wasser) und lasse 1 Tag stehen, damit sich Spuren von Phosphorsäure als gelber Niederschlag ausscheiden können. Die abgegossene Lösung ist dann absolut rein and arbeite ich schon seit $1 / 4$ Jahre mit solchen Lösungen; ohne jemals Differenzen mit den amtlichen Versuchsstationen gehabt zu haben. Dieses Verfahren ist einfacher als alle anderen und sind die Mengen etwa gelöster Molybdänsäure in den Waschwassern sehr unbe- 
342 Bornträger: Ueber eine einfache Aufarbeitung der Molybdänrückstände etc.

deutend. Ich habe einmal circa $100 l$ Waschwasser noch auf Molybdänsäure verarbeitet, indessen nur wenige Gramme einer dazu noch sehr unreinen Molybdänsäure erbalten, weshalb ich davon abrathe.

Hinsichtlich der Phosphorsäurebestimmung mittelst der Molybdänmethode gehen meine Ansichten zunächst dahin, dass es nicht rathsam ist, wie mehrfach vorgeschlagen wird, den Niederschlag von Ammoniummagnesiumphosphat krystallinisch zu erhalten, sondern ich ziehe die Pulverform vor.

Ich verfahre folgendermaassen:

Die ammoniakalische Lösung des gelben Niederschlages versetze ich mit rauchender Salzsäure bis der Niederschlag sich, wie schon R. Fresenius empfiehlt, nicht sofort löst. Durch die rauchende Salzsäure wird die Mischung sehr heiss, was die Ausfällong begünstigt. Alsdann fälle ich mit Magnesiamixtur und filtrire $a b$, sobald aus dem pulvrigen Niederschlage Luftblasen aufsteigen. Dieses ist in der Regel nach 1 bis 2 Stunden der Fall. Die Molybdänfällung stelle ich in heisses Wasser bis zum Rande, und dauert anf diese Weise eine Analyse höchstens $3 / 4$ Tage bis Alles fix und fertig ist, das heisst die Auflösung des Superphosphates bis zum Wägen des Niederschlages.

Macht man dagegen fast neutral und fällt ganz heiss mit Magnesiamixtur, wie vorgeschlagen, so erhält man allmählich, nicht sofort einen krystallinischen Niederschlag. Die Fällung dauert viel länger, haftet sehr fest am Glase, fällt unvollkommen aus und der getrocknete Niederschlag. staubt sehr stark beim Eintragen mit dem Pinsel in den Tiegel. Ausserdem entweicht das Ammoniak schwerer beim Glühen als sonst.

Zum Schlusse empfehle ich noch den Niederschlag sammt dem Filter zusammen zu veraschen, da ich noch keine Differenzen dadurch gefunden habe und Zeit gespart wird.

Zum Glühen eignet sich ganz besonders der neue Spiritus-Brenner von $\mathrm{H}$. Barthel in Dresden, ${ }^{1}$ ) den ich schon seit $1 / 2$ Jahre benutze. Wie ich bereits früher erwähnte, ist ein Gebläse bei dem Glühen ganz unnütz; ich glühe stets mit der einfachen Flamme, erst ganz gelinde, dann immer stärker und konnte noch niemals in meinen Niederschlägen nach dem Glühen Ammoniak nachweisen. Während nun im Gebläse die Platintiegel sehr leiden, hat der von mir hier benutzte Platintiegel nach 350 Analysen noch nicht $1 \mathrm{mg}$ am Gewichte abgenommen. Ich schreibe dieses nur dem Barthel'schen Brenner. zu, da der Spiritas eine

1) Vergl. diese Zeitschrift 30, 596; 31, 67; 32, 208. 
reinere Flamme liefert als das Leuchtgas, durch dessen Schwefelgehalt and Theergehalt leicht Schwefel- und Kohlenstoff-Platin entsteht, was hier ganz undenkbar ist, da der Spiritus frei davon ist.

Ich kann daher den Herren Collegen, selbst denen, die Gasleitung haben, den neuen Barthel'schen Spiritus-Brenner nicht genug empfehlen, da er den Tiegel schont und genaue Analysen ermögliclit.

Holleschau i. Mähren.

Apparat zur Herstellung von $50 \mathrm{~mm}$ Wasserdruck bei der Bestimmung des Kältepunktes der 0ele. Von

\section{F. Gantter.}

Die Herstellung eines gleichmässigen Luftdrucks von $50 \mathrm{~mm}$ Wassersänle zur Bestimmung des Kältepunkts der Oele wird mit Hülfe eines in Wasser getauchten umgekehrten Trichters bewirkt. Die zu diesem Zweck gewöhnlich benutzte Vorrichtung ist aber nicht bequem in der Handhabung und nimmt auch viel Platz ein. In einfacher und bequemer Weise lässt sich mit dem in Fig. 13 abgebildeten Apparat $^{1}$ ) arbeiten, den ich seit. längerer Zeit in meinem Laboratorium benutze. Derselbe besteht aus dem zweiarmigen Kölbchen A, in dessen Hals ein mit einem Glashahn c versehenes Trichterrohr B mittelst eines durchbohrten
Fig. 13.

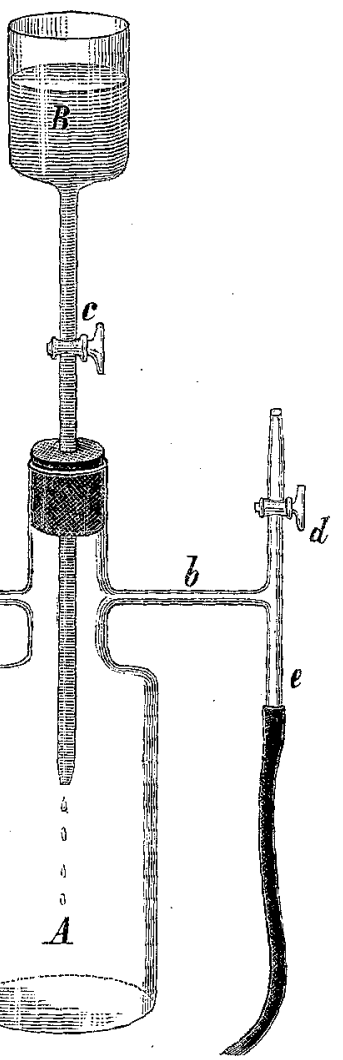

1) C. Desaga in Heidelberg fertigt den Apparat nach meiner Angabe an. Fresenius, Zeitschrift f. analyt. Chemie. XXXIII. Jahrgang. 